DOI: $10.47456 / k r k r . v 1 i 9.32870$

\title{
Conectados para aprender: Whatsapp, Facebook, QR Code e Google sala de aula
}

\author{
Connected to learn: whatsapp, facebook, qr code and google classroom \\ Fabio Togneri Telles \\ Lais Pavani Delfino
}

\begin{abstract}
Resumo: A pandemia chegou. Diante dos desafios enfrentados pela sociedade como um todo, com as escolas não poderia ser diferente. Iniciamos o ano letivo em fevereiro, conforme calendário escolar e tudo parecia transcorrer normalmente, quando, abruptamente, as aulas foram interrompidas. Faz seis meses e continuamos em casa, escolas fechadas, espaços silenciosos e vazios. Numa perspectiva de conectar a todos, em uma única corrente, pensamos em criar condições para tal e, principalmente, para a grande maioria, sem internet, através do wi-fi da escola, disponibilizado pela Secretaria Municipal de Educação - Cachoeiro de Itapemirim. Com todas as medidas de segurança, através de rodízio de turmas, no entorno da escola, ao ar livre, passamos a receber os alunos. Assim, o presente artigo, de caráter qualitativo e característica investigativa, realizada com os alunos do $6^{\circ}$ ao $9^{\circ}$ ano do Ensino Fundamental, no município de Cachoeiro de Itapemirim, que por meio dele pode-se a habilidade de leitura, interpretação e elaboração de texto através do aplicativo $Q R$ CODE. O estudo apresenta um plano de ação como metodologia, a fim de trabalhar resolução de problemas matemáticos tendo como base Malba Tahan. A partir dos resultados satisfatórios acredita-se que somos capazes de ser criativos e fortes, para enfrentar os desafios, porque vimos escola, alunos, pais e comunidade se articulando em tempos nunca vividos por nossa geração.
\end{abstract}

Palavras-chave: Pandemia. Desafios. Aprendizagem.

Abstract: The pandemic has arrived. Given the challenges faced by society as a whole, schools could not be different. We started the school year in February, according to the school calendar and everything seemed to be going smoothly, when, abruptly, classes were interrupted. It has been six months and we are still at home, schools closed, quiet and empty spaces. In a perspective of connecting everyone, in a single chain, we thought about creating conditions for this and, mainly, for the vast majority, without internet, through the school's wi-fi, made available by the Municipal Department of Education - Cachoeiro de Itapemirim. With all the security measures, by rotating classes, around the school, outdoors, we started to receive students. Thus, this article, of a qualitative character and investigative characteristic, carried out with students from the 6th to the 9th grade of Elementary Education, in the municipality of Cachoeiro de Itapemirim, which through it can be the ability to read, interpret and write text through the QR CODE app. The study presents an action plan as a methodology, in order to work on solving mathematical problems based on Malba Tahan. Based on the satisfactory results, we believe that we are able to be creative and strong, to face the challenges, because we saw school, students, parents and the community articulating in times never before experienced by our generation.

Keywords: Pandemic. Challenges. Learning. 


\section{Introdução}

Com o avanço tecnológico, planeja-se deixar de lado o ensino baseado na memorização, na cópia, proporcionando atividades que deixarão o aluno mais autônomo e apto a desenvolver a sua própria técnica de estudo, tornando-se protagonista do seu próprio conhecimento, desenvolvendo o pensamento crítico. Especificamente, a Base Nacional Comum Curricular (BNCC) destaca a valorização dos conhecimentos construídos no mundo digital considerando os discentes como aprendizes ativos e criativos e não apenas consumidores de tecnologia (BRASIL, 2017).

Ao analisar a Base Nacional Comum Curricular (BNCC) de Ciências, observa-se a orientação para o uso de tecnologias digitais em sala de aula. $O$ uso destas tecnologias tem como característica principal proporcionar aos alunos o contato com processos, práticas e procedimentos da investigação científica para que eles sejam capazes de intervir na sociedade. Dessa forma, as vivências e interesses dos estudantes sobre o mundo natural e tecnológico devem ser valorizados (BRASIL, 2017).

Porém, o conhecimento geralmente pode ser visto nas escolas como algo pronto e acabado, infelizmente, é tido como verdade absoluta, transmitido mecanicamente para o aluno, que é apenas um repetidor daquilo que foi repassado ou pensado por alguém, sem que seja permissível refletir sobre o que está sendo repassado em sala de aula. Com isso, o processo de construção e reconstrução de novas ideias, pensamentos e conceitos se quebram. Dessa forma, torna-se necessário que todos os envolvidos nos processos de ensino e aprendizagem constituam a verdadeira vanguarda ante as incertezas do nosso tempo.

Assim sendo, torna-se necessário recorrer ao meio tecnológico, onde o professor deve enquadrar suas aulas, tornando-as mais prazerosas e marcantes na vida dos jovens de hoje. Dessa forma, a escola localizada na periferia da cidade de Cachoeiro de Itapemirim, , com baixo poder aquisitivo, com carência de espaços culturais e esportivos, onde os alunos dispõem de televisão como meio de comunicação, com celulares dos pais, quando possuem, sem computador e Internet, na sua maioria. 
Em meio à pandemia, isolamento social, ensino remoto, como atingir a todos ou a grande maioria? Numa tempestade de ideias, alguns profissionais da escola e mães, preocupados com o pouco envolvimento dos alunos, e as dificuldades apresentadas, pensaram na internet da escola. Estabeleceu-se diálogo escola - família. As duas educam para viver no mundo, no entanto, ambas as instituições não vêm conseguindo o sucesso almejado e buscam parceria para amenizar estes tempos de pandemia. Este cenário endêmico, econômico e social trouxe mudanças para a escola e suas relações.

Passados os primeiros momentos da pandemia ${ }^{1}$, modestamente movimentos de aprendizagem, através da TV aberta, com coletâneas preparadas pelos professores, para manterem os alunos ativos e produtivos. A partir dos mês de julho, o municipio disponiblizou o acesso ao Google Sala de Aula $^{2}$, gerando uma maior proximidade com os alunos, porém ainda, aulas remotas.

Ainda assim, ficou à margem um grande contingente de alunos, sem condições tecnológicas de acompanharem as demandas presentes. Encurtamos caminhos e propusemos esperança para muitos, na disponibilidade do wi-fi da escola, quando se sentiram conectados e mais próximos da mesma. Como era de se esperar, os alunos saudosos da escola estão vindo aleatoriamente, sob rigoroso sistema de organização e segurança, seguindo as normas da Secretaria de Saúde, acessar a internet e finalmente cumprirem as atividades.

A escola na sua organização administrativa, com alguns profissionais presentes, vem monitorando, o movimento na área externa da mesma, para garantia da funcionalidade e orientação de uso, do referido meio de acesso, inclusive dando suporte àqueles que apresentam dificuldade para a realização das tarefas.

\footnotetext{
${ }^{1}$ A pandemia pode ser definida como uma situação em que uma doença infecciosa se espalha de forma rápida e descontrolada para vários locais, podendo atingir proporções mundiais, ou seja, não está restrita apenas a uma cidade, região ou continente.

2 É uma ferramenta simples e intuitiva e que tem como objetivo facilitar a vida de alunos e professores. O professor consegue criar e gerenciar turmas e atividades, além de distribuir tarefas, fazer avaliações e enviar feedbacks
} 
Enquanto preparávamos o espaço de acesso à internet, por algumas vezes, fomos interpelados por mães de alunos, com dúvidas e dificuldades em orientarem os filhos no cumprimento dos deveres. Ali vimos, constatada a veracidade dos fatos que originaram tal ação. Na realidade, para muitos, a tecnologia é um grande desafio, quando não sabem ou têm receio e insegurança no enfrentamento das contendas atuais.

Nunca se valorizou tanto o espaço escolar, as relações interpessoais, o contato direto do professor com o aluno, como organizador e gerenciador das aprendizagens. Há de se refletir e repensar o papel do professor na educação, valorizando-o como instrumento de grande alcance e mentor dos alicerces das gerações.

$\mathrm{Na}$ era da informação, a BNCC reconhece os benefícios da cultura digital nas esferas sociais, por meio dos avanços tecnológicos e a multiplicação de celulares e computadores relacionados ao hábito do consumo dos jovens (BRASIL, 2017), dessa forma a transição de modelos e padrões de ensino impõe desafios a serem enfrentados por quem ensina e quem aprende. De essa maneira ensinar é diferente de aprender, porque ensinar é um processo social, no qual cada um desenvolve um estilo próprio, dentro do que é traçado para todo o grupo. Assim educar é considerado como a colaboração que se tem para que professores e alunos transformem suas vidas em processos permanentes de aprendizagem.

Diante do exposto planeja-se, proporcionar atividades que deixarão o aluno mais autônomo e apto a desenvolver a sua própria técnica de estudo, tornando-se protagonista do seu próprio conhecimento, desenvolvendo o pensamento crítico.

\section{Procedimentos metodológicos}

É uma habilidade do Projeto Pedagógico do município de Cachoeiro de Itapemirim trabalhar anualmente com os alunos a leitura, interpretação e elaboração de textos em todas as disciplinas, logo, começamos no ano de 2019 com o projeto de leitura usando como recurso o aplicativo QR CODE. 
Como dissemos anteriormente, no início de 2020, quando não se falava em pandemia, tranquilamente alguns professores, especificamente na área de Matemática, começaram novamente a desenvolver o projeto de leitura, solicitado pela escola, utilizando a disciplina a partir dos ensinamentos de Malba Tahan "Leitura dos desafios de Malba Tahan através de recursos tecnológicos". Estes vieram a justificar a nossa caminhada até a proposta atual do wi-fi, para todos.

De acordo com Tardif (2014, p.125), "Ensinar é perseguir fins, finalidades. Em linhas gerais, pode-se dizer que ensinar é empregar determinados meios para atingir certas finalidades".

Ainda de acordo com Tardif (2012), a experiência é muito mais do que uma categoria para representar os saberes dos professores, eles se constituem na verdade enquanto "o núcleo vital do trabalho docente" (TARDIF, 2012, p.54). Em outras palavras, a afirmação do autor permite a constatação de que o saber da experiência é de certa forma o alicerce que sustenta o trabalho cotidiano do professor. Assim:

Pode-se chamar de saberes experienciais o conjunto de saberes atualizados, adquiridos e necessários no âmbito da prática da profissão docente e que não provem das instituições de formação nem dos currículos. Estes saberes não se encontram sistematizados em doutrinas ou teorias [...] (TARDIF, 2012, p.49).

Neste sentido, utilizamos o aplicativo QR CODE como recurso, com a finalidade de incentivar os alunos a buscarem diferentes formas de solucionar e compreender conteúdos básicos da grade curricular. Ainda iniciamos novas metodologias, o Google Meet ${ }^{3}$, o Google Forms ${ }^{4}$ e o Google Classroom.

Com base nas contribuições de Tardif (2014), elaborou-se um Plano de Ação constituído de etapas e foram acrescentadas outras atividades, em função da Pandemia da Corona Vírus, em face das aulas remotas, da

3 O Google Meet é uma ferramenta que permite a conexão entre as pessoas por videoconferência, uma forma ágil e eficiente de se manter em dia com as tarefas escolares ou de trabalho.

4 O Google Forms é um serviço gratuito para criar formulários online. Nele, o usuário pode produzir pesquisas de múltipla escolha, fazer questões discursivas, solicitar avaliações em escala numérica, entre outras opções. A ferramenta é ideal para quem precisa solicitar feedback sobre algo, organizar inscrições para eventos, convites ou pedir avaliações. 
dificuldade de acesso e do ensino à distância. Optamos por propor, como já sinalizamos anteriormente, o wi-fi da escola. Tal proposta deu origem e justifica o tema, do PRÊMIO GESTÃO ESCOLAR - 2020, da nossa escola CONECTADOS PARA APRENDER: WHATSAPP, FACEBOOK, QR CODE E GOOGLE SALA DE AULA.

Sendo assim elaborou-se as etapas a seguir:Como ação de partida, a escola propôs a pintura do muro principal, com imagens alusivas ao tema, com ênfase nas ferramentas tecnológicas de comunicação, utilizadas: Celular, Whatsapp, Facebook, QR CODE e outros.

- Utilização do grupo "Matemática Maria" - facebook, para apresentar o aplicativo, QR CODE, através de textos (o que é o QR CODE);

- Organização dos alunos para baixarem o aplicativo, QR CODE, nos celulares (comando e familiarização com o aplicativo, realização de leitura do código em alguns produtos, como pasta de dente, remédio, alimento e cupom fiscal);

- Apresentação da biografia de Malba Tahan, através de vídeos (disponíveis no Facebook);

- Solicitação de um resumo sobre a Malba Tahan e o aplicativo;

- Analise dos desafios e as metodologias de resoluções do autor, através de códigos gerados pelo aplicativo (os desafios serão estudados de acordo com a série do aluno;

- Socialização com a escola e comunidade, de espaço externo,nos arredores da mesma, marcação de espaços, uso de máscara,entre outros, como geradores de oportunidades.

\section{Resultados e discussão}

Com a finalidade de trabalhar a habilidade leitura, interpretação e elaboração de textos, a escola desenvolveu um projeto de leitura usando o QR CODE como recurso. Neste tópico iremos apresentar as análises dos dados da pesquisa. 
A prática foi desenvolvida durante o ano de 2019 e 2020.Vale a pena ressaltar que o projeto deu início em 2019 com a apresentação do aplicativo aos alunos, ou seja, criamos um grupo no facebook e whatsapp afim de apresentar teoricamente o app aos alunos, assim os educandos conheceram e baixaram o app nos celulares. Assim sendo, pode-se destacar que o facebook e whatsapp como forma pedagógica, fazendo com que uso em grupos para deixar recados, incentivos ou mesmo propor atividades, bem como criar grupos de discussão com os educandos que, além disso, podem propor e sugerir ideias e também ser definido como outro canal de comunicação entre o professor e os educandos. A partir desse momento trabalhamos a habilidade solicitada, através da definição do QR CODE.

O desenvolvimento desta atividade foi uma tentativa de apresentar o ensino de matemática de forma contextualizada, problematizadora e com atividades que fizessem sentido na vida do aluno. Sendo assim, a partir das atividades e leituras de textos históricos, os alunos puderam reconhecer conceitos aplicadosa sua vida cotidiana e a novas situações.

Sabe-se que a alfabetização científica se apoia na compreensão do conceito de alfabetização associada à capacidade de compreensão da ciência e da tecnologia. Sendo assim vai além do simples domínio psicológico e mecânico das técnicas de ler e escrever. Sendo assim, pode ser entendida como conjunto de práticas sociais.que usam a escrita e a tecnologia, em contextos específicos para objetivos específicos. Almejando a formação crítica dos estudantes para o domínio e uso dos conhecimentos científicos e seus desdobramentos nas diferentes esferas de sua vida.

Portanto as atividades desenvolvidas tiveram o objetivo de promover o desenvolvimento dessas habilidades em consonância com os três eixos estruturantes que estabelecem a base para uma prática educativa que vise a Alfabetização Científica (SASSERON; CARVALHO, 2008). O primeiro eixo estruturante corresponde à "compreensão básica de termos, conhecimentos e conceitos científicos fundamentais"(SASSERON; CARVALHO, 2008, p.75), destaca a importância da construção de conhecimento científico necessário aos alunos para aplicações em diversas situações do cotidiano. O segundo 
eixo a "compreensão da natureza das ciências e dos fatores éticos e políticos que circundam a prática" (SASSERON; CARVALHO, 2008, p.75) mostra a importância de tratar a ciência como um conjunto de conhecimentos sujeitos a mudanças. E, finalmente, o terceiro e último eixo compreende ao "entendimento das relações existentes entre ciência, tecnologia, sociedade e meio ambiente" (SASSERON; CARVALHO, 2008, p.76), na intenção de conscientizar os alunos sobre a relação que existe entre as diferentes esferas.

Dessa forma, os alunos foram organizados em grupos, isso devido a alguns alunos não terem celular, para realizar a leitura de códigos, $Q R C O D E$, de produtos como pasta de dente, remédio, alimento e cupom fiscal. $O$ interessante é que os alunos tiveram a oportunidade de adquirir bula de medicamento e site de produtos através da leitura do código disponível no produto. Isso causou uma curiosidade nos educandos, os mesmos queriam criar seus próprios códigos, foi aí que os educadores iniciaram a criação de códigos para representar a leitura dos problemas matemáticos de Malba Tahan.

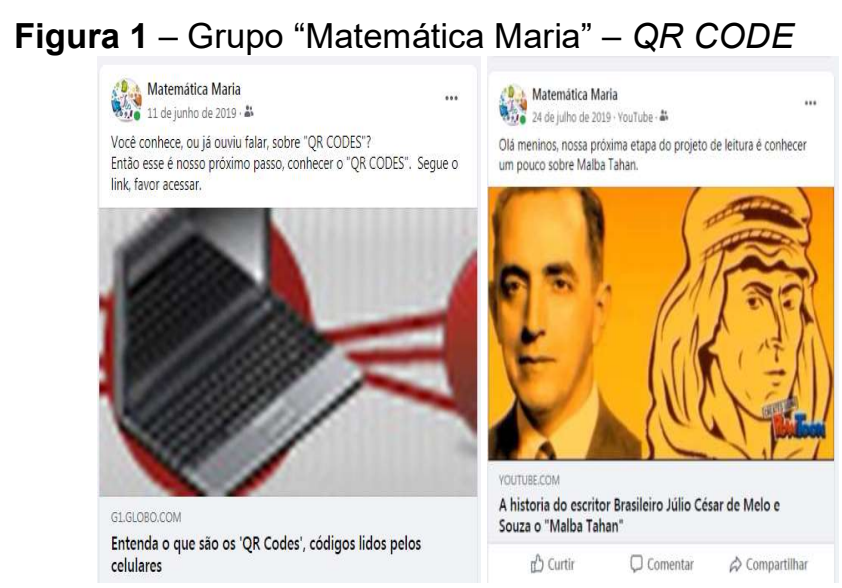

Fonte: Elaboração própria dos alunos

Assim, iniciamos o ano de 2020 dando sequência ao projeto, uma vez que os alunos já conheciam o app e os problemas de Malba Tahan.Iniciamos o projeto da seguinte maneira:

$1^{\circ}$ ) Cada grupo selecionava um código $Q R C O D E$ disponibilizado pelo educador;

$\left.2^{\circ}\right)$ Em seguida, realizava a leitura do código, através do app no celular, para identificar o desafio de Malba Tahan; 
$\left.3^{\circ}\right)$ Identificado o desafio cada grupo tinha que analisar o método de resolução do problema e argumentar de forma defensiva a resolução, ou seja, se o grupo achasse que a resolução do problema estava errado, tinha que elaborar uma outra resolução justificando sua resposta. Muitos alunos disseram que a resolução do problema estava trazendo vantagem ao calculista, assim elaboraram outras formas de resolução, porém chegava ao mesmo resultado; $\left.4^{\circ}\right)$ A resolução do problema de cada grupo era apresentado ao professor através de um código $Q R C O D E$ gerado pelo grupo de alunos.

A intenção final era apresentar um esquete ${ }^{5}$, cada grupo iria elaborar uma pequena encenação da resolução do problema, porém, de acordo com MORIN (2000), que nos revela que a noção do caráter incerto faz com que a ação e/ou o ato pensante torne-se oportuno ao conhecimento desejado, ou seja, a incerteza do conhecimento legitima a oportunidade da reflexão acerca do desejado, dessa forma aconteceu o inesperado, PANDEMIA.

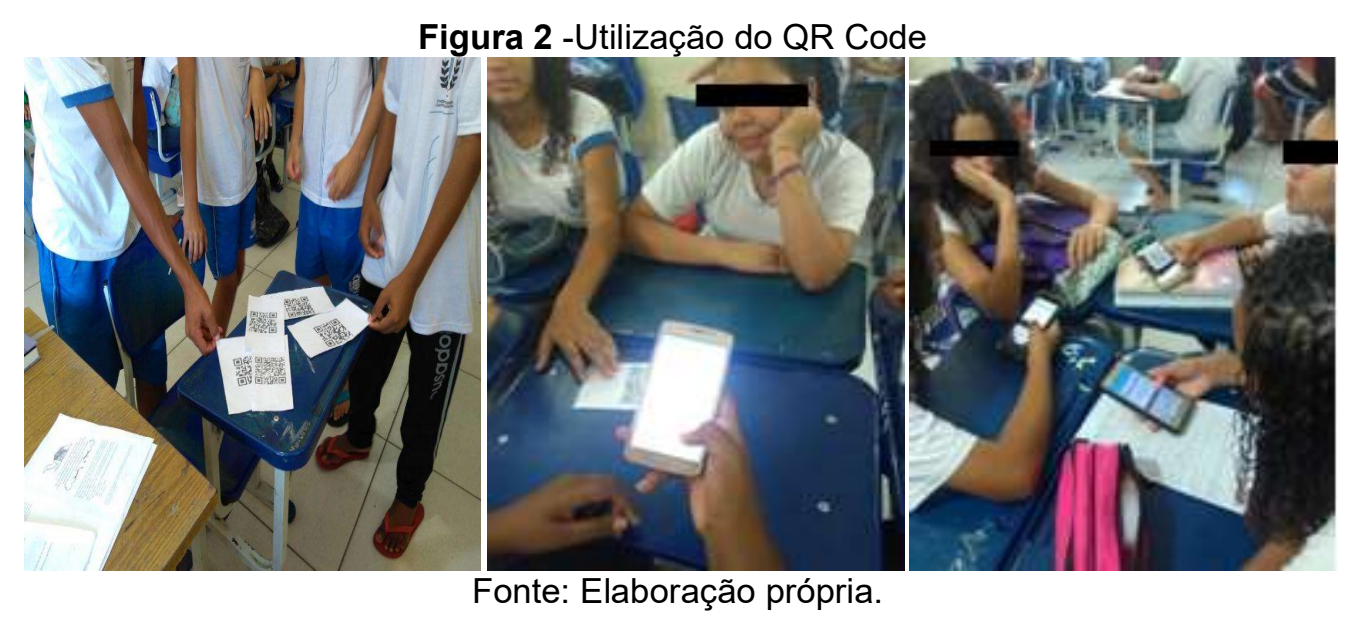

Foi aí que iniciamos uma nova metodologia de ensino, google sala de aula, dessa forma nossas aulas passaram a ser remotas. Com esse novo modelo de esino aprendizagem a escola disponibilizou o acesso a internet para os alunos, logo os alunos podiam acessar o wi-fi da escola para cumprir com as atividades, foi assim que conseguimos dar seguência ao projeto de leitura. Lembrando que todo esse processo foi realizado de acordo com os requisitos

\footnotetext{
${ }^{5}$ Esquete é uma peça de curta duração, geralmente de caráter cômico.
} 
da saúde, respeitamos o espaço de distanciamento devido, assim como o uso de máscaras e álcool em gel.

Como é de nosso conhecimento, tudo que é novo requer um tempo para aprender e para iniciar o projeto não foi diferente, foi necessário um tempo para adaptação dos educandos ao portal e utilizar o wi-fi na escola. Então continuamos usando como apoio o whatsapp. Depois de algumas semanas, ja familiariados com o portal, iniciamos vídeos conferências como recurso de ensinagem através do google meet, realizamos um cronograma de aula online, na qual os alunos tinham acesso para exclarecimentos e auxílios

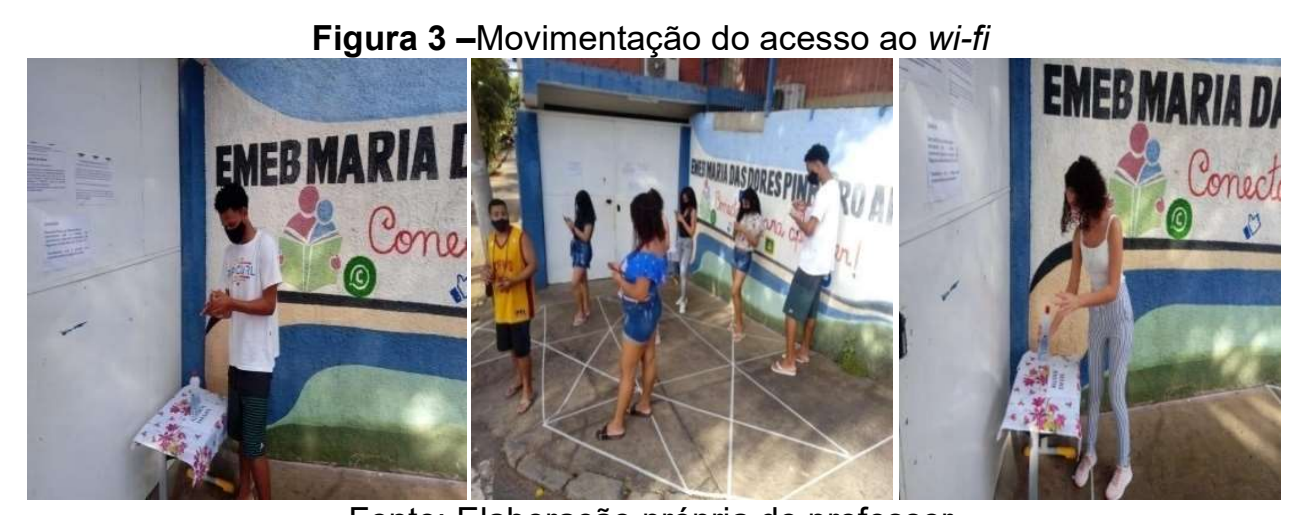

Fonte: Elaboração própria do professor.

Figura 4 - Aula on-line através do Google Meet

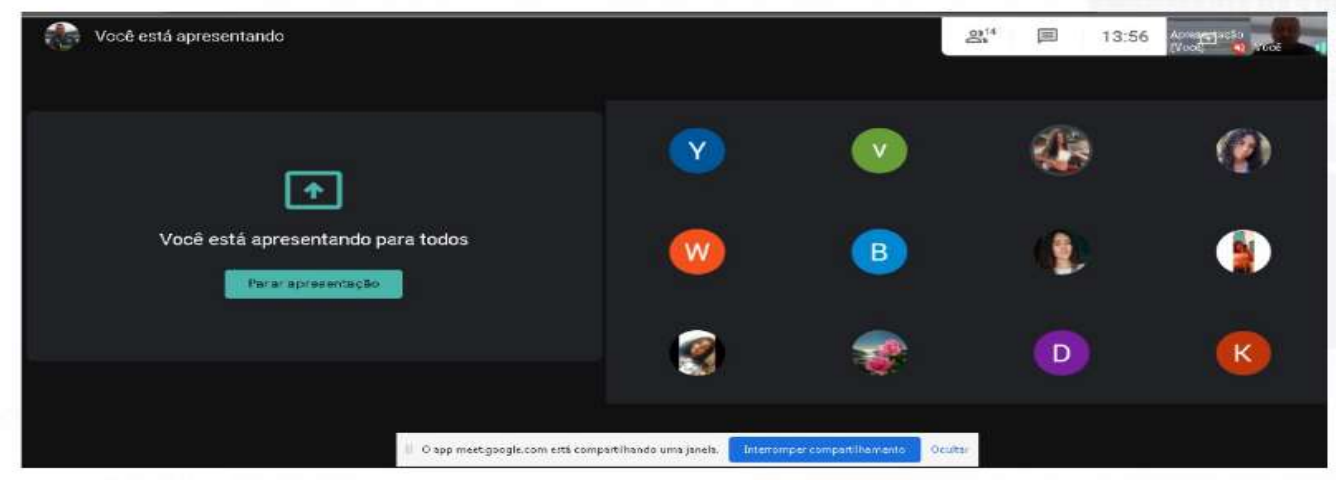

Fonte: Elaboração própria do professor.

Como forma de socialização com a escola e comunidade, realizamos a pintura do muro principal da escola. Vale a pena ressaltar que todo o design criado foi elaborado pelos alunos. 


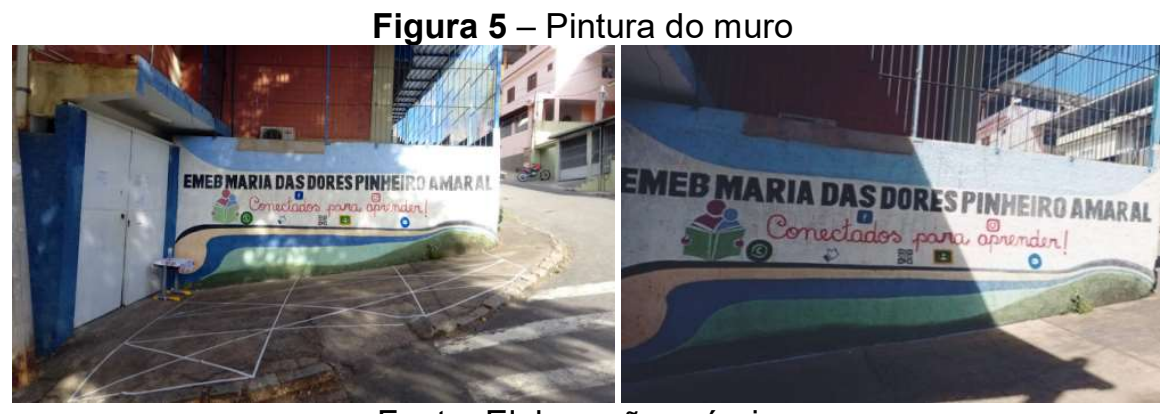

Fonte: Elaboração própria.

\section{Conclusão}

Primeiramente defende-se que a utilização das Sequência de Ensino Investigativas nas mais diversas estratégias de ensino, como a experimentação, leitura de textos, discussões, questões matemáticas, vídeos, entre outras estratégias estimulem a reflexão dos alunos. Nas atividades ficou nítido que é possível realizar aulas contextualizadas e significativas, em que o aluno seja o construtor de seu próprio conhecimento, além do desenvolvimento de habilidades como análise, reflexão e comparação.

No decorrer da atividade é necessário observar que o professor é um mediador e possui papel significativo, tendo a obrigação de buscar alternativas viáveis para fazer desaparecer o desinteresse dos alunos que não querem se envolver e participar de projetos implantados na escola. Para Tajra: "os professores precisam estar abertos para incorporar essa nova realidade e estar abertos para as mudanças, sua nova postura é de facilitar processo de ensino aprendizagem" (2000).

Deve-se considerar que para que ocorra aprendizagem de algo novo é necessário participação, comprometimento, envolvimento e inovação. Dessa forma, pretende-se diminuir as dificuldades de aprendizado do aluno, bem como motivar as aulas, procurou-se analisar e observar as etapas e aplicação de uma SEI (sequência de ensino investigativa).

Para Carvalho (2013, p. 9), a SEl pode ser descrita como uma sequência de atividades que abrange um tópico do programa escolar onde cada atividade planejada deve buscar a interação dos conhecimentos prévios do aluno com os novos de maneira que possa passar do conhecimento 
espontâneo ao científico, buscando entender os conhecimentos já estruturados por gerações anteriores.

Para Morin (2000, p.55) o uso da tecnologia é um grande apoio à educação, tornando-se uma âncora indispensável à educação, sendo assim propicia para alunos e professores, uma nova forma de ensinar e aprender, integrando valores e competências nas atividades educacionais.

É necessário considerar a contribuição do grupo, de profissionais da escola, para a realização desse projeto, diante das condições em que as escolas se encontram em especial os nossos professores, foi fundamental.

Apesar de todas as dificuldades presentes numa comunidade carente, podemos dizer que está dando certo, o wi-fi está para todos.

Somos professores, estamos sempre sonhando e perseguindo nossos sonhos, há de ser com mais presença, entre afagos, abraços, com os sorrisos dos alunos, à nossa frente, que haveremos de seguir.

Continuando no plano das expectativas, torcemos para que, numa situação mais confortável e segura, possamos retomar nossos papéis, nos conformes anteriores, porém, nada será como antes. Continuaremos usando dos recursos tecnológicos experimentados com mais frequência e conhecimento. O contato com o professor, na sala de aula presencial, certamente será mais valorizado. Os pais terão nas experiências vividas, quando se viram professores em casa, opiniões mais claras e reais do papel do professor na aprendizagem dos seus filhos.

Conforme Morin (2000) surge uma nova consciência do nosso cotidiano, já que o ser humano vive em constantes mudanças, e que o enfrentamentoao "desconhecido" é um dos sete saberes necessários à educação do futuro.

Por issoque, esta deve se voltar para as incertezas ligadas ao conhecimento. Dessa forma é necessário considerar a importância do diálogo com as famílias pelo whatsapp e outro meio propiciou espaços para o estabelecimento de vínculos e vem oferecendo segurança a educadores, estudantes e familiares, sendo possível demonstrar que todos estão empenhados nos mesmo propósitos: criar uma rede de relações que resulte na 
formação de sujeitos capazes de enfrentar diferentes e complexas situações na vida, de fazer escolhas positivas, diante delas, respeitando e valorizando seu contexto e seus pares. É importante que a escola volte a ser um ambiente escolar acolhedor, em que todos (crianças e adolescentes) se sintam acolhidos e pertencentes, sobretudo diante do mundo altamente complexo em que vivemos.

O diálogo e a parceria entre escolas e famílias são essenciais para o sucesso e a formação integral dos estudantes, no entanto, tem sido muito comum haver discussões sobre as responsabilidades que recaem sobre a escola em função da ausência ou mesmo displicência dos familiares na formação dos filhos, já que eles também depositam expectativas enormes sobre o que os alunos devem aprender em casa. Há também certo consenso de que será necessário ampliar o interesse e a participação das famílias na vida escolar.

Segundo Rosa Maria Torres (1999, p.104):

É preciso rever os próprios parâmetros sobre os quais se assentam a premissa da "participação" em educação. Participar quer dizer, literalmente, tomar parte de algo, algo que é diferente e externo a nós [...] Por anos, décadas, temos pedido a pais de família e comunidades que "participem" da escola e da educação escolar dos seus filhos. Nesta concepção, família (F) e escola (E), comunidade (C) e escola (E) aparecem como dois mundos diferentes, e o vínculo entre eles como uma ponte de uma só via. Pede-se a $F$ que se aproxime da $E$, que vá até a $E$, que solicite a $E$. Pede-se a $C$ que tome parte da $E$, que intervenha na $E$, que colabore com a E (TORRES, 1999, p.104).

A experiência nos uniu mesmo distantes, porque vimos escola, alunos, pais e comunidade se articulando em tempos nunca vividos por nossa geração. Descobrimos que, como humanos, somos capazes de sermos criativos e fortes, para enfrentarmos os desafios, porém é necessário estarmos preparados para compreender e aceitar a imprevisibilidade. 


\section{Referências}

BRASIL. Ministério da Educação. Base Nacional Comum Curricular. Ministério da Educação, Brasília, DF: MEC, 2017. Disponível em: $<$ http://basenacionalcomum.mec.gov.br/>.

BRIGHENTI, et.al. Metodologias de ensino-aprendizagem: uma abordagem sob a percepção dos alunos. Revista GUAL, Florianópolis, v.8, n.3, p.281-304, set.2015.

CARVALHO, Anna Maria Pessoa de. Ensino de ciências por investigação: condições para implementação em sala de aula. São Paulo: Cengage Learning, 2013.

CARVALHO, Anna Maria Pessoa de. Ensino e aprendizagem de Ciências: referenciais teóricos e dados empíricos das sequências de ensino investigativas (SEI). In: Marcos Daniel Longgini. (Org). O uno e o Diverso na Educação: EDUFU, p. 253-266. 2011.

CARVALHO, Anna Maria Pessoa de. O Ensino de Ciências e a proposição de sequências de ensino investigativas. Ensino de Ciências por investigação: Condições para implementação em sala de aula. São Paulo: Cengage Learning, v. 1, p. 1-19, 2018.

CARVALHO, Anna Maria Pessoa de; OLIVEIRA, Carla M. Alvarenga de; SASSERON, Lucia Helena; SOUZA, Luciana Sedano de; BASTITONI; SILVA, M. Investigar e Aprender Ciências 5. ano. 2011. (Desenvolvimento de material didático ou instrucional - Coleção Investigar e Aprender).

MORAN, José Manuel; MASETTO, Marcos T.; BEHRENS, Marilda Aparecida. Novas tecnologias e mediação pedagógica. Campinas: Papirus, 2000.

MORIN, Edgar. Os Sete Saberes Necessários à Educação do Futuro. 2a . ed. São Paulo: Cortez: Brasília-DF:UNESCO,2000(P.47-115)

NEVES, lara Conceição Bitencourt; SOUZA, Jusamara Vieria; SCAFFER, Neiva Otero; GUEDES, Paulo Coimbra; KLUSENER Renita. Ler e escrever: compromisso de todas as áreas. 6a. Ed. - Porto Alegre: Editora da UFRGS,2004.

TARDIF, Maurice. Saberes docentes e formação profissional. $4^{\text {a }}$ Ed. Rio de Janeiro: Vozes, 2002.

TARDIF, Maurice; LESSARD, Claude. O trabalho docente: elementos para uma teoria da docência como profissão de interações humanas. $6^{\mathrm{a}} \mathrm{Ed}$. Rio de Janeiro: Vozes, 2011.

TARDIF, Maurice. Saberes docentes e formação profissional. $14^{a}$ ed. Petrópolis, RJ: Vozes, 2012.

TAHAN, Malba. O homem que calculava. $86^{a}$ ED - Rio de Janeiro: Record, 2014. 
TAJRA, S. F. Utilização de recursos pedagógicos de ambientes virtuais como complemento para atividades presenciais no ensino superior. Virtual Educa, 2005.

PEREZ, Tereza (Org). Diálogo escola - família: parceria para a aprendizagem e o desenvolvimento integral de crianças, adolescentes e jovens - São Paulo: Moderna, 2019.

\section{Sobre os Autores}

\section{Fabio Togneri Telles}

fabiotogneritelles@gmail.com

Professor da Rede Publica Municipal de Cachoeiro de Itapemirim, com licenciatura em Matemática (São Camilo - ES, 1997) e Licenciatura em Fisica (UFES - 2019) mestrando em Fisica pelo IFFluminense, polo 34.

\section{Lais Pavani Delfino}

lpdelfino@hotmail.com

Professora da Rede Publica Municipal de Cachoeiro de Itapemirim, com licenciatura em Matemática (IFES ) 